\title{
Features of Internal Waves in a Shoaling Thermocline
}

\author{
Vadim V. Navrotsky ${ }^{1}$, Valeriy Yu. Liapidevskii ${ }^{2}$, Elena P. Pavlova ${ }^{1}$ \\ ${ }^{1}$ V.I.Il'ichev Pacific Oceanological Institute, Far-Eastern Branch of Russian Academy of Sciences, Vladivostok, Russia \\ ${ }^{2}$ M.A. Lavrentiev Institute of Hydrodynamics, Siberian Branch of Russian Academy of Sciences, Novosibirsk, Russia \\ Email: vnavr@poi.dvo.ru, liapid@hydro.nsc.ru, epavlova@poi.dvo.ru
}

Received April 13, 2013; revised May 17, 2013; accepted June 14, 2013

Copyright (C) 2013 Vadim V. Navrotsky et al. This is an open access article distributed under the Creative Commons Attribution License, which permits unrestricted use, distribution, and reproduction in any medium, provided the original work is properly cited.

\begin{abstract}
Observations and numeric modeling of internal wave generation and transformation in the shelf zone of sea show that the main part of tidal energy is transported to shores in form of internal gravitational waves. Long-term measurements of temperature and current velocity fluctuations at many levels in the near-bottom thermocline were carried out during the periods when stable seasonal thermocline was present. Analysis of the measurements permits us to understand mechanisms of internal wave destruction with turbulent motion generation and corresponding rebuilding of velocity and density mean fields in the stratified near-bottom layer. Spectral analysis of temperature fluctuations shows that in shoaling internal waves the low-frequency maxima disappear, maxima at higher frequencies appear, and the spectra slope in the high frequency range changes with depth. Taking into account the concurrent analysis of near-bottom pressure fluctuations and current velocity fluctuations from surface till bottom we come to the conclusion that breaking internal waves in a near-bottom thermocline generate not only small-scale three-dimensional turbulence, but also quasi-horizontal turbulence of larger scales, which considerably contributes into mixing and sediments, alluvium, and nutrients transport in the shelf zone of sea.
\end{abstract}

Keywords: Shelf; Shoaling Thermocline; Internal Waves; Turbulence

\section{Introduction}

Huge energy of tides and inertial motions is dissipated in oceans' coastal waters, but in stably stratified flows the initial stage of the energy transformation is generation of internal waves (IW) over the continental slope and shelf break. It is evident that all energy of IW is dissipated before they can reach shores, but it is little known about distribution of that energy between turbulence, work against buoyancy, currents, and transport of bottom sediments and other admixtures.

Analysis of numeric modeling and the previously obtained data on IW propagation [1,2] have shown that there may be several different ways of IW evolution, depending on vertical structure of water density, kind of forcing, and distance between thermocline and bottom. As an example of our numeric calculations, a part of the process of IW generation by tidal motions over continental slope and shelf boundary is shown in Figure 1. Tidal fluctuations for that run were specified as integral flow, corresponding to harmonic fluctuations of velocity in the section from depth of $100 \mathrm{~m}$ till surface with the amplitude $20 \mathrm{~cm} / \mathrm{s}$. Density was set constant from surface till $20 \mathrm{~m}$, then augmenting linearly till $50 \mathrm{~m}$ with a gradient corresponding to the mean Brunt-Vaisala period about 1 min, then again constant till bottom. The continental slope steepness was $1 / 10$ between the depths 1000 and $100 \mathrm{~m}$. The left boundary is placed in the open sea 100 $\mathrm{km}$ from the shelf boundary, which is taken as a point with the depth $100 \mathrm{~m}$ and horizontal coordinate $100 \mathrm{~km}$.

At the moment $24 \mathrm{~h}$ after switching on tidal currents with 12 hours periodicity from the state at rest we can see a group of IW with rather steep front and appearance of internal waves of the second vertical mode above the shelf boundary. At that moment tidal flow is moving to a shore, the next wave, outlining distinctly an internal tide (IT), is forming above the shelf break, and the internal tide's front moves forward living behind a tail of sinusoidal waves with decaying amplitudes (see the moment $\mathrm{t}=$ $27 \mathrm{~h}$ ). After the moments of reverse from rising to low tide $(\mathrm{t}=30 \mathrm{~h}$ in our case) the IW phase velocity sharply decreases and their steepness increases (see the picture at $\mathrm{t}=33 \mathrm{~h}$ ). In that phase nonlinear effects become maximum, and in the time span between $33 \mathrm{~h}$ and $36 \mathrm{~h}$ very steep high amplitude frontal waves generate packets of shorter waves, which must fall behind the longer waves. Long tails of waves with decreasing amplitudes are 

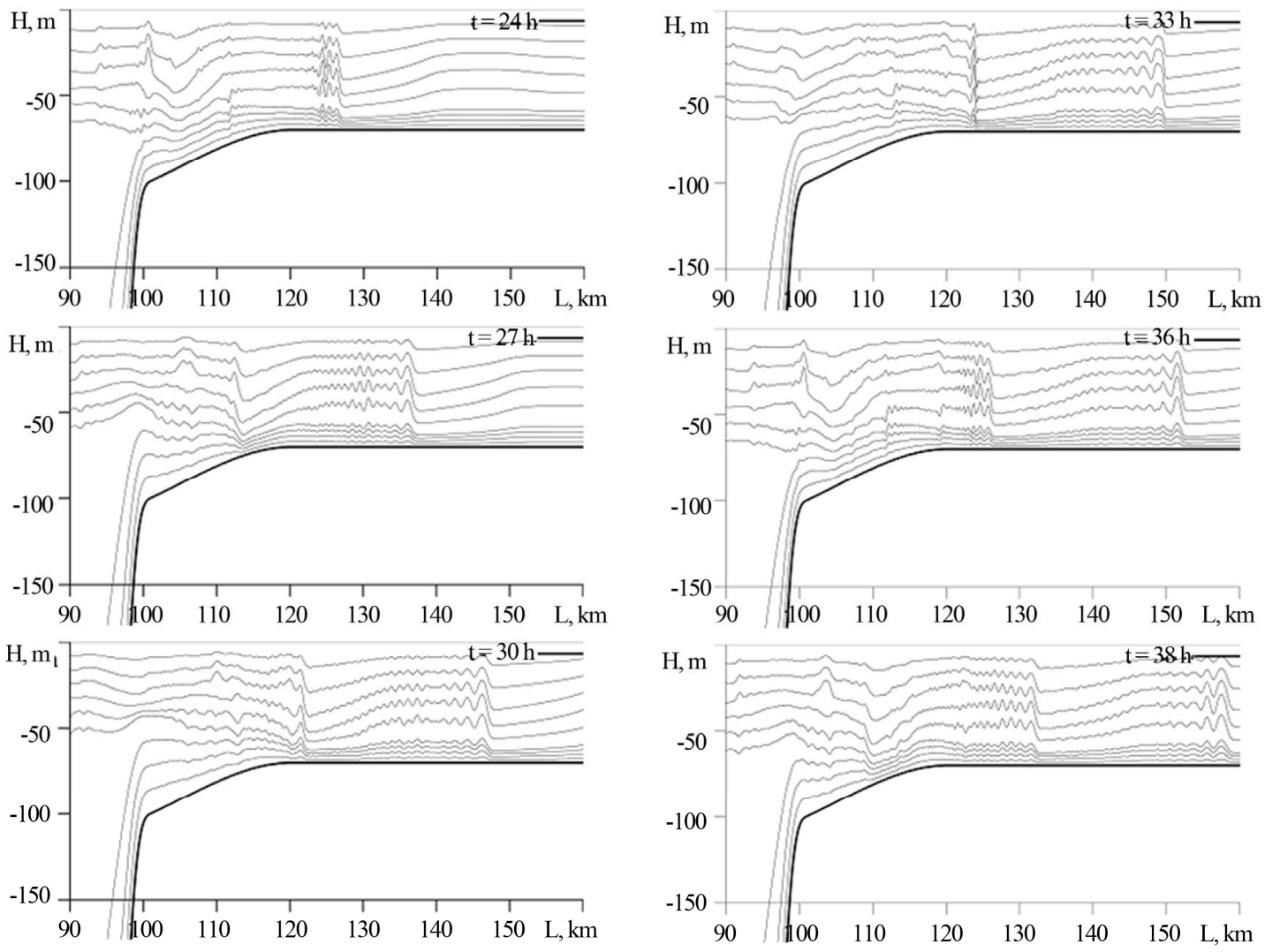

Figure 1. Spatial structure of isopycnals fluctuations, representing IW field at different moments after switching on the 12-hour barotropic tide from the state at rest.

formed in the beginning of the next rising tide (see the moments $36 \mathrm{~h}$ and $38 \mathrm{~h}$ ).

We see that in the process of IW generation the zone above the shelf break and time spans of reverse from ebb to rising tide are critical, because there and then the IW can break due to supercritical steepness. The main characteristic features of the IW fields obtained in our numerical experiments are considerable transformations in space and time, formation of sharp fronts, resembling bores or hydraulic jumps, and short-wave packets behind them. In the runs with sharp thermocline small groups of solitons were formed, which were transforming into packets of short sinusoidal waves and back into smaller solitons in the time of propagation. Breaking of IW was obtained in the runs with high tidal velocity and sharp thermocline, and in most cases it occurred at the ebb phase close to the shelf boundary or far from the shelf boundary in a shoaling thermocline. The connected with IW processes in coastal ocean are complex, frequently including coexistence of wave and turbulence, and they are the main object of our field investigations.

Far from shores, where the lower boundary of a thermocline is far from bottom, energy of IW serves to change mean density structure and form vertical fine structure. These phenomena were explained as a result of internal wave-induced mixing within the thermocline that can be effective mechanism for generation of multi-layered structures (vertical fine structure) in a coastal ocean $[2,3]$. The changed vertical structure parametrically changes IW properties - dispersion relations, lengths, phase and group velocities, and energy spectrum. These nonlinear transformations can go on practically without IW breaking till the zones, where thermocline begins to feel bottom. A spatial transect of typical temperature structure in the Japanese Sea shelf zone (south from the cape Gamov) is shown in Figure 2, where we can see the sharp thermocline with internal waves that is going to contact bottom at depths between 20 and 30 meters.

Evidently, waves with high amplitudes feel bottom earlier, than waves with small amplitudes. In any case the final result is turbulent dissipation, but just that waveturbulence transition and its consequences are insufficiently investigated, though they are important for many geophysical, biological and ecological processes in coastal zones. The deserved attention was paid to them in theoretical and experimental works during the last decade [4-11], but in most cases analysis was limited only by wavy motions. Our main goals are to see how and where waves become "not waves" and what phenomena accompany that process in the near-bottom thermocline. 


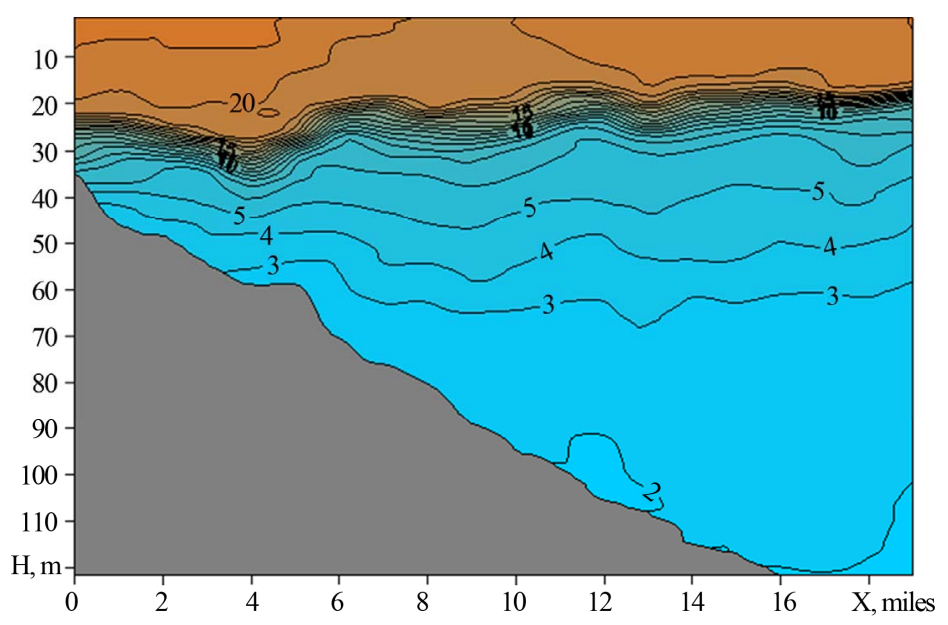

Figure 2. Thermocline and IW shoaling in the shelf zone of the Sea of Japan (09.09.2010).

\section{Instrumentation and Observations}

In shallow parts of shelf zones nearly homogeneous temperature and density distributions are observed almost till the bottom, and it was generally supposed that IW can not propagate there. But more detailed laboratory and in sea measurements $[8,12]$ have shown that wavelike activity can exist in near-bottom layers rather far from the zone of thermocline contact with bottom. Here we are presenting some preliminary results of our measurements in such layers.

Investigations of IW dynamics and transformations in a shoaling thermocline were carried out on the hydrophysical polygon "Cape Shulz" of the V.I.Il'ichev Pacific Oceanological Institute in the southern part of the Peter the Great Bay, Sea of Japan (Figure 3). The polygon location permits not only to adjust and fine-tune new methods of measurements, but also to test and validate the modern methods of oceanic processes modeling. Among hydrodynamic processes that are highly active in the ocean coastal zone are inertial motions and mesoscale eddies, internal tides and short-wave packets of IW generated over the continental slope, and vertical and horizontal turbulence caused by IW breaking and by current shear instability. Internal gravitational waves in a wide range of frequencies and wave numbers are the most permanent process, because water density stable stratification is observed at intermediate depths or close to bottom practically in the all seasons.

To perform long-term measurements of IW and turbulence parameters the special equipment was constructed, including sensors of temperature and pressure, telemetric system of data gathering and processing, and corresponding soft to obtain detailed information on IW transformation in the near-shore zone. The basic temperature processor was microchip 1-Wire ${ }^{\circledR}$ Digital Thermometer DS18B20 of the firm "Dallas semicondoctor". The accuracy of temperature measurements was

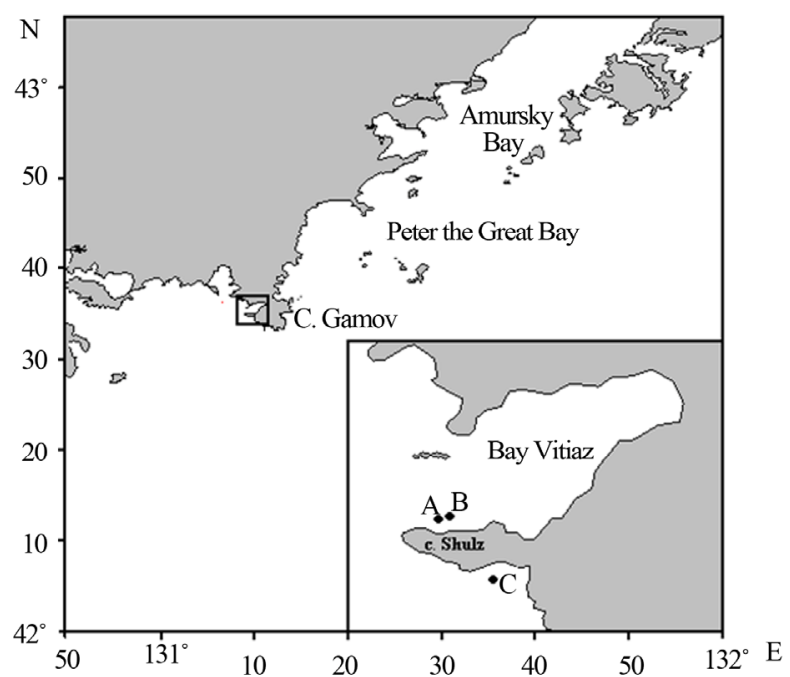

Figure 3. Map of region and position of stationary measuring systems.

$0.1^{\circ} \mathrm{C}$ in the range from $-5^{\circ}$ till $+40^{\circ} \mathrm{C}$. Time constant of the sensors was $3 \mathrm{~s}$, but to protect them from mechanical damage they were placed into special cylindrical containers. In this way their time constant in our observations was $8 \mathrm{~s}$. The characteristic periods of non-tidal IW in the investigation aria being $10-120 \mathrm{~min}$, the presented system insured measurement of real IW and turbulence with time-scales greater than $20 \mathrm{~s}$.

The measurements of temperature were performed in the near-bottom layer at fixed points in the bay Vitiaz (A, B) and in the sea outside the bay (C) at 20 or 30 levels with separation of $0.5 \mathrm{~m}$. Signals from the sensors were transferred to the shore-based computers in two waysby underwater cable (in the open sea) and by radio (in the bay). A special program was developed to decode the signals, store them in files and present in graphic form on monitors. In this way constant control of the measuring process was possible. The information was periodically 
transferred via internet into the Institute's data base. Measurements of current velocity profile with the help of RDCP-600 and pressure fluctuations with the help of SBE26 were made close to the strings with thermistors. Transects with probing of temperature, salinity and other parameters were fulfilled in different conditions from July till November.

\section{Results and Discussion}

In Figure 4 is shown a typical transformation of temperature vertical structure along transects in south-north direction from the shelf boundary to the point $\mathrm{C}$ (Figure 2). The very sharp thermocline, which generally is observed before continental slope, deepens, broadens, and vertical fine structure is formed. It was shown by Navrotsky et al. [2] that such transformation can be due to nonlinear interactions of internal waves with the non homogeneous field of temperature. That process is intensified nearer to the shore because nonlinearity of IW becomes stronger in a shoaling thermocline. So in most cases our strings anchored at depths between 15 and 30 meters embraced the layers, where IW become steep and can break.

Typical temperature fluctuations, registered by 20 sensors, installed $0.5 \mathrm{~m}$ apart from one another in a $10 \mathrm{~m}$ thick near-bottom layer, can be seen in Figure 5 (for convenience only ten sensors with $1 \mathrm{~m}$ separation are shown). Rather evident are different transformations of temperature fluctuations with depth: in some cases we see maximum amplitudes at lower levels (as in the time spans between $0-12 \mathrm{~h}$ and around 60 and $72 \mathrm{~h}$ ), in other cases maximum fluctuations are at upper levels (as in the time spans near 36 and 48 hours). Very high amplitudes of temperature fluctuations (5 - 10 degrees) close to bottom are observed, which correspond, with through-layer drop of temperature about $10-15$ degrees, to amplitudes of vertical motions practically equal to the stratified bottom layer thickness. Most of the significant fluctuations are coherent at all levels, that is, they are due to internal waves.

The second important feature of the process is alternation of zones with well defined quasi-periodic fluctuations and zones with absence or very weak fluctuations (see the range $60-120 \mathrm{~h}$ and $240-276 \mathrm{~h}$ ). There can be three causes of that IW intermittence. The first is related to the fact that prevailing time intervals between such zones were about 12 and 24 hours or in some other days about $17-18$ hours, which are close to the periods of tidal and inertial motions in the region. And they are just the periodicities of intense IW packets generation near the shelf boundary. The second cause may be set-downs and set-ups of water by off-shore and on-shore winds. With on-shore wind the near-bottom cold water is displaced to greater distance from a shore, and IW become impossible in homogeneous warm water at the observation point. The third and the most interesting cause can be IW breaking with subsequent turbulent mixing and density vertical gradients vanishing. The small-scale three-dimensional turbulence could not be measured with our devices, but consequences of its action can be visible in some cases.

A section of temperature field in the time-depth plane

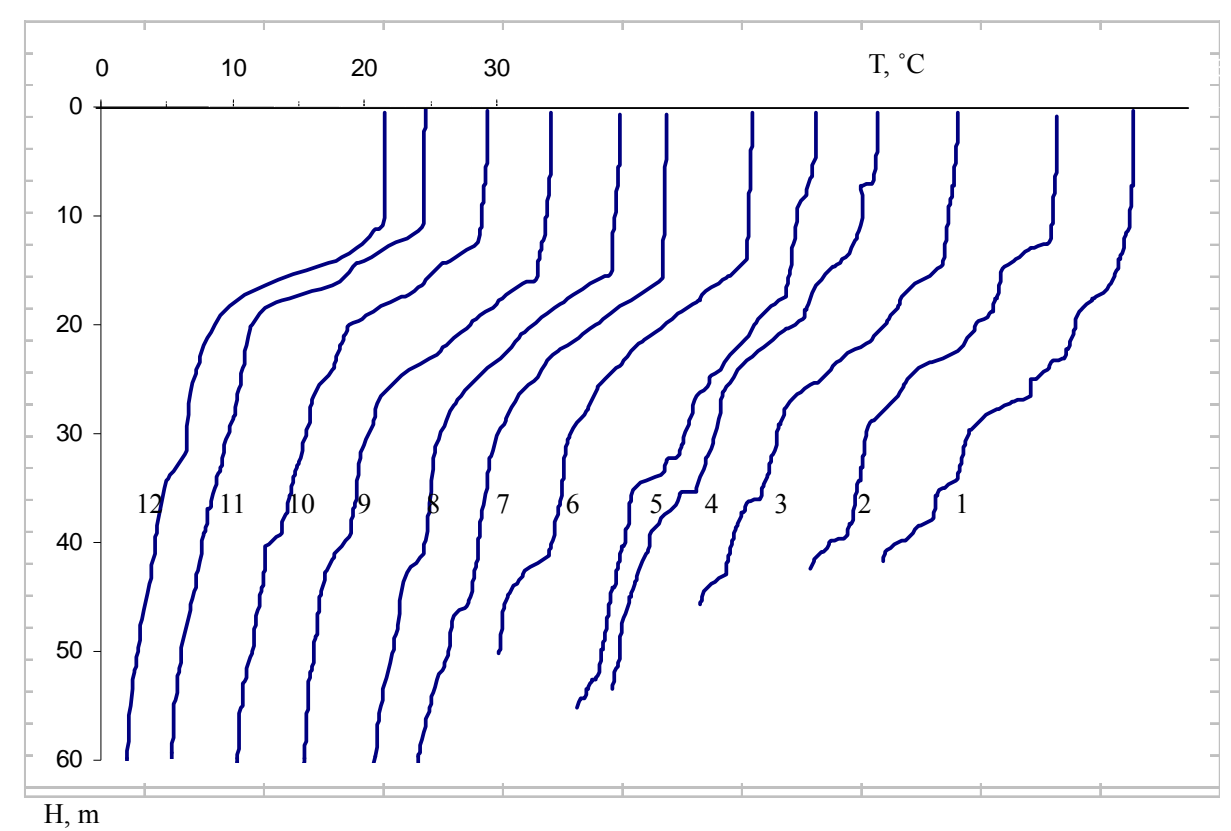

Figure 4. Temperature profiles on a transect from the shelf break to the shore (from left to right). The temperature scale is shown for profile 12, the others are sequentially shifted by $5^{\circ} \mathrm{C}$. Distance between soundings is 1 mile. 

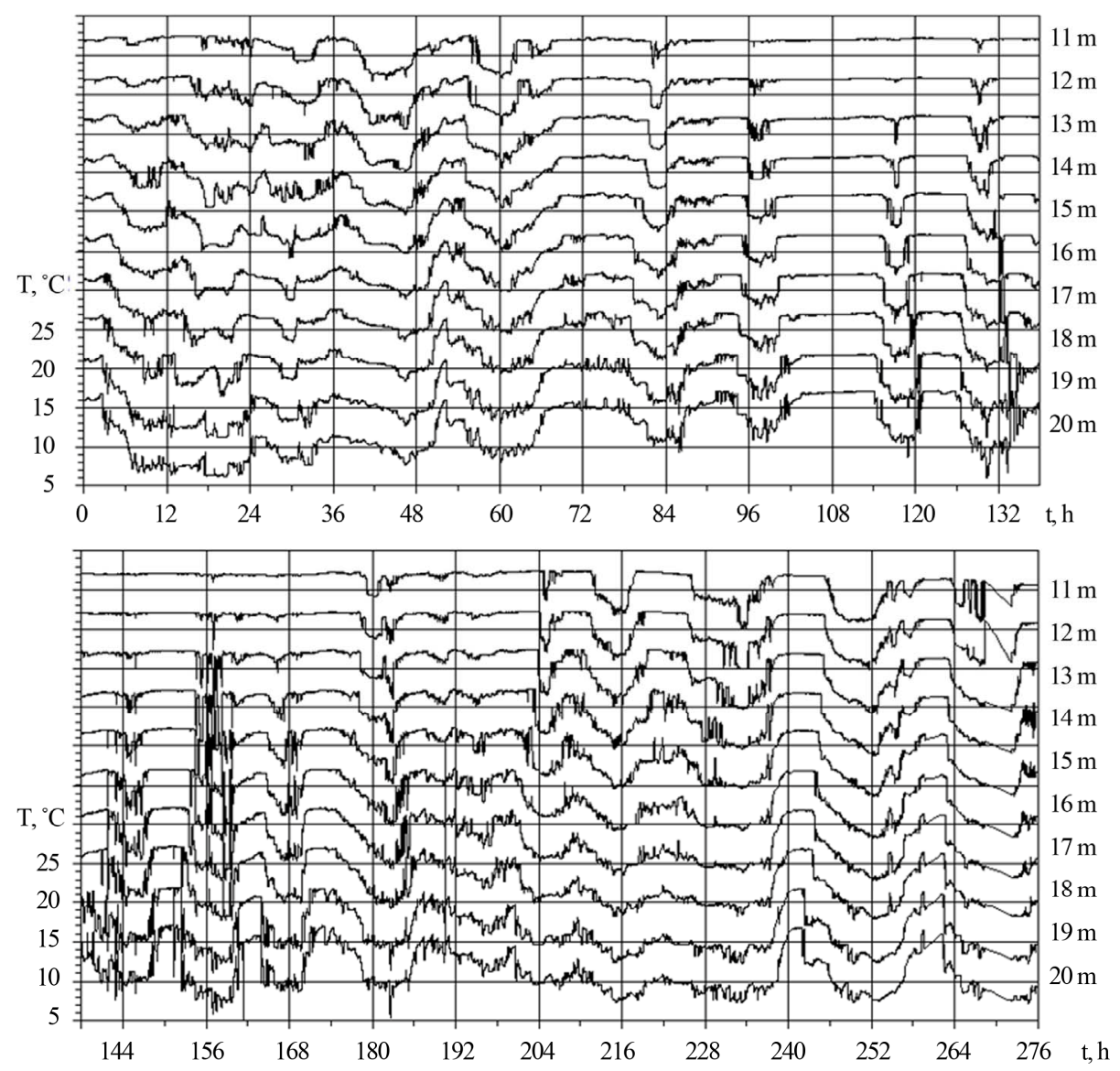

Figure 5. Temperature fluctuations in a 10-meter layer of the near-bottom thermocline (September, 2009). The scale for temperature is given for the lower sensor; the others are shifted $5^{\circ} \mathrm{C}$ up.

is shown in Figure 6. During the first three days only the lower part of the thermocline contacts bottom with quasitidal periodicity, but then we see that well mixed warm water penetrates almost to the bottom, and IW are transforming into moving parcels of stratified cold water. Big parcels, having about 12-hour time scale, are due to internal tides (IT), but inside them there are undulations with much shorter periods. The amplitudes of the all fluctuations grow gradually. Though these stable and stratified volumes of cold water can produce quasi-periodic fluctuations of temperature, they are more like "boluses", than familiar waves. After $144 \mathrm{~h}$ the boluses' height quickly grows, and then abrupt transition to quasi homogeneous vertical structure takes place near the $168 \mathrm{~h}$, after which only low and short parcels of cold water close to bottom are observed. We believe that here we have just the case of the IW-generated boluses breaking, and the following process can be interpreted as IW setup into a shallow zone of warm mixed water, where continuous thermocline is absent, and IW can not propagate. Parcels of rather low and short volumes of cold water, intruding into warm water after $168 \mathrm{~h}$ with quasi-tidal periodicity, seem to support that interpretation.
In numeric simulation and in observations high frequency waves are generated simultaneously with internal tides or as a result of their nonlinear transformations over a sloping bottom. The scattering of IT into high-frequency waves is intensified in the process of IT breaking, and corresponding short boluses can penetrate farther along sloping bottom and nearer to shores, than the IT-produced setup. We suggest that two possibilities can be realized: 1) internal tide breaking directly into smallscale turbulence and 2) its scattering into high-frequency short waves with subsequent their breaking into turbulence. In the case of strong thermocline the second possibility is more probable, and its realization is shown in Figure 7. The packet of short-period waves has an envelope with tidal time-scale (Figure 7(a)), and we can suppose that the short-period waves are generated as a result of an internal tide nonlinear transformation. More detailed picture of short-period waves in Figure 7(b) shows that they are highly nonlinear on the verge of breaking and have trapped cores of cold water transported to shores.

In Figure 8, we can see another possibility: setup of the short-period waves, which were generated independ- 

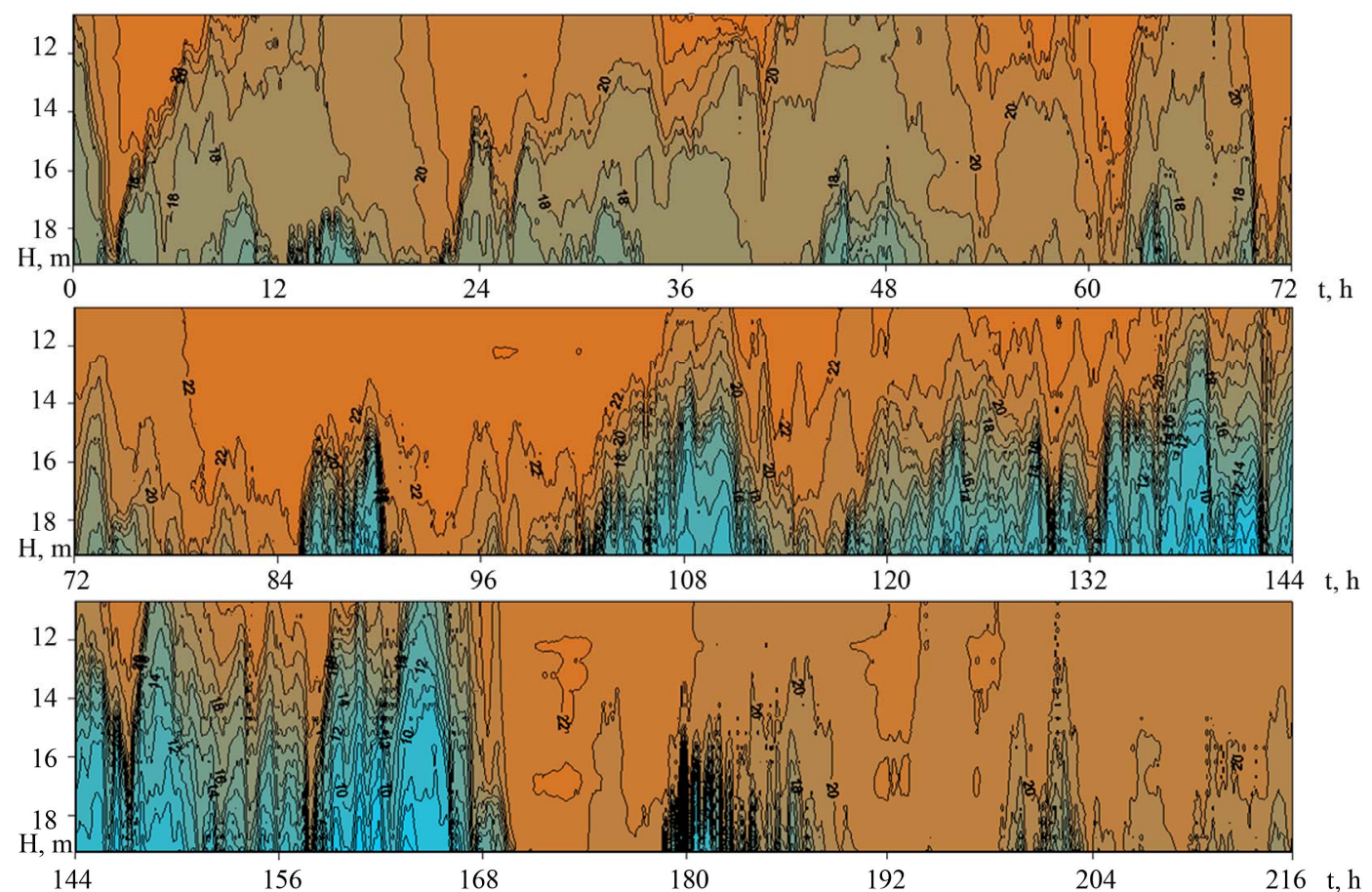

Figure 6. Section of temporal fluctuations of temperature in the 10-meter-thick near-bottom layer (start of observations at 11:35, 31.08.2010).
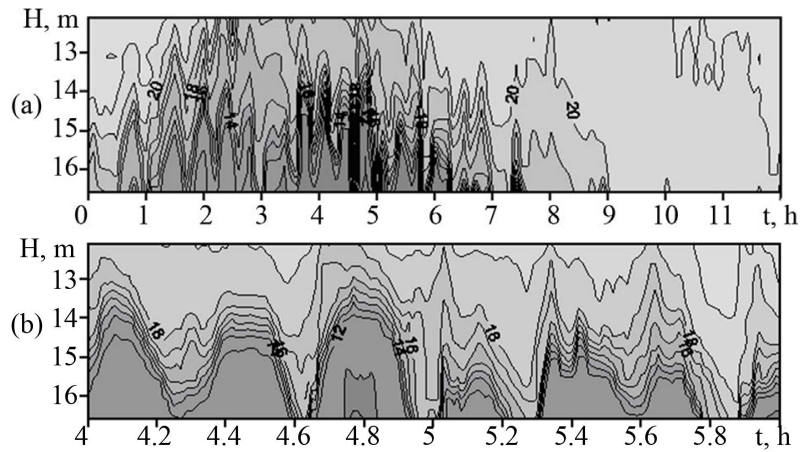

Figure 7. Fluctuations of isotherms in the 5-meter thick near-bottom layer: (a) a 12-hour piece of records; (b) refinement of the process between 4 and 6 hours of the upper picture.

ently of internal tides and can have different from IT phase velocities. It is evident that in absence of continuous thermocline the propagating volumes of cold water, which have time-scales from 12 till 2 - 4 hours, are not real waves. Some of the boluses still have trapped cores of cold water, but their outer parts are clearly turbulent, and full breaking with turbulent dissipation must happen not far from the observation location. The process of breaking leads to intense vertical mixing and to rapid transition of internal wave energy into energy of turbulence and advancing bottom currents.

The process of alternation of homogeneous warm water from surface to bottom with parcels of much colder
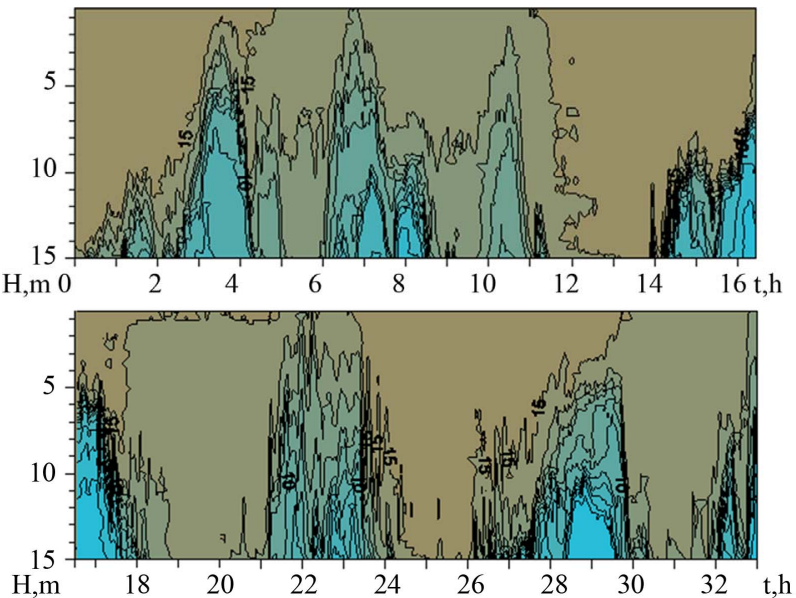

Figure 8. Setup and destruction of short-period internal waves in the $15 \mathrm{~m}$ thick near-bottom layer (start of measurements at 06:22, 01.09.2011).

water of 5 - 10 meters thick will naturally lead to nearbottom pressure fluctuations. Their effects must be especially important in shallow waters due to high relation of IW heights to local depth. Power spectrum of pressure fluctuations, measured close to bottom at the depth of 20 $\mathrm{m}$ during 42 days in August-September, is shown in Figure 9. Besides distinct maxima at tidal periods 24 and $12 \mathrm{~h}$, we see the peaks, corresponding to long-term fluctuations with the periods 2 and 8 days, which can be caused by synoptic processes in sea and atmosphere. The well pronounced maxima are in the range of internal 


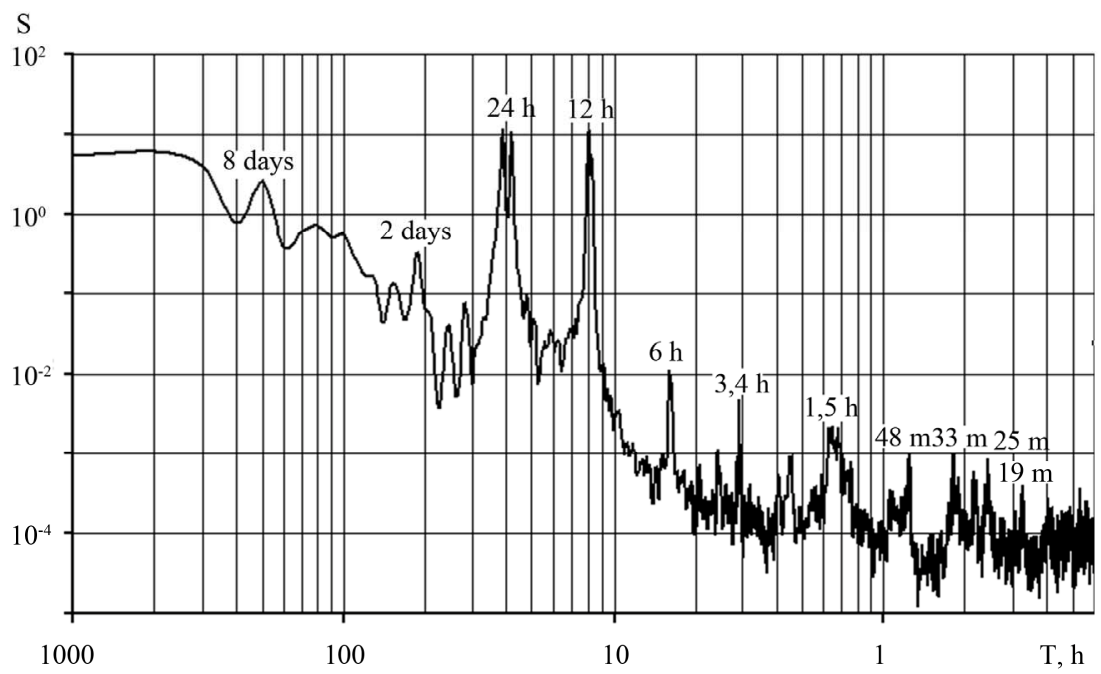

Figure 9. Spectrum of near-bottom pressure fluctuations at the depth of 20 meters (2008, August-September).

gravitational waves and possible seiches, and there is rather weak energy attenuation in the range of prevailing IW periods from 6 hours till 10 minutes.

Special attention should be given to the differences between our spectra and spectra of pressure fluctuations obtained by van Haren [10], which were rather smooth in the range of periods from several hours till several minutes. The difference can be due to the fact that van Haren's measurements were made in the conditions, when internal-wave continuum could be formed. In our case the IW field is highly intermittent and mixed with boluses (see Figures 6-8). Our situation seems to be more intricate and important for the problem of manifold effects of IW in near-shore zones. A notable rise of energy close to the highest frequency in Figure 9 can correspond to the bump in the range of several minutes in the van Haren's spectra.

A similar picture can be seen in the spectrum of temperature fluctuations close to bottom at the depth $16 \mathrm{~m}$ (Figure 10). In that case increased levels of energy are close to the local Brunt-Vaisala frequency. We believe that such phenomenon can be due to the secondary generation of short internal waves by turbulent eddies from the friction layer (wall turbulence). The similar explanation is suggested by van Haren (wave-turbulence coupling), though he does not specify the mechanism of turbulence generation.

The most important feature of temperature fluctuations that can be seen in Figure $\mathbf{1 0}$ is change of their spectral structure with depth inside the near-bottom layer from the exponential low $f^{-3}$ at the upper level to $f^{-5 / 3}$ at the lower level ( $0.5 \mathrm{~m}$ above the bottom). At the upper level $12 \mathrm{~m}$ we see a linear section with the slope -3 in the range from $17 \mathrm{~h}$ to about $1 \mathrm{~h}$ (with a small peak around $2.5 \mathrm{~h}$ ), then considerable energy elevation in the range 50 $20 \mathrm{~min}$ and again quasi-linear section with the same slope -3 from 20 till $3 \mathrm{~min}$. From $3 \mathrm{~min}$ till the end point corresponding to $2 \mathrm{~min}$ the spectrum leveling begins to show. Spectra for the deeper levels 13 and $14 \mathrm{~m}$ retain the same form only slightly diminishing the bulge in the range $50-20 \mathrm{~min}$. At levels 15 and $16 \mathrm{~m}$ the spectra become quasi-linear with a general slope about $-5 / 3$ except for the high frequency ending part $(4-2 \mathrm{~min})$ with 3 rather notable maxima.

The slope -3 for internal waves in shelf zones was obtained in the result of many measurements analyzed in [2] and some other papers, but here we have rather different picture. The spectral form similar to spectra at levels 12 , 13 and $14 \mathrm{~m}$ with a bulge between $50-20 \mathrm{~min}$ is typical for most of our measurements of temperature fluctuations in near-bottom layers, and we are going to propose its theoretical explanation in a separate paper. Following the theoretical considerations in [13], the spectrum proportional to $f^{-5 / 3}$ can be produced by horizontal turbulence with the rate of kinetic energy dissipation as determining parameter.

The transition of energy from internal waves in upper parts of the near-bottom thermocline into horizontal turbulence in its lower parts seems natural from the physical point of view. In highly nonlinear and breaking nearbottom internal waves the upper water particles overrun the lower ones. That leads, as a consequence of continuity, to high upward vertical velocities inside the wave body and to compensating horizontal velocities in its lower layers. In that way quasi-horizontal turbulence must be generated in close to bottom layers in addition to small-scale three-dimensional turbulence, characteristic for bottom friction layers.

To show more clearly that process we calculated averaged by 3 hours horizontal and vertical momentum fluxes from surface till bottom (Figure 11). The horizontal momentum flux, represented as averaged product 


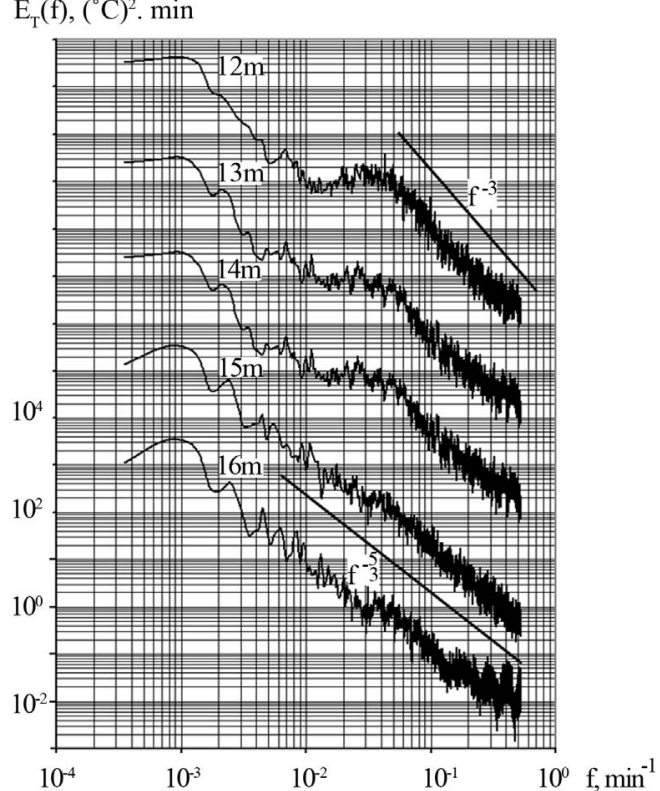

Figure 10. Spectra of temperature fluctuations at different levels. The frequency scale is given for the $16 \mathrm{~m}$ level, for each next level it is shifted two orders up. of current horizontal components $\boldsymbol{u}$ and $\boldsymbol{v}$ in Figure 11(a), is very high in the upper layer due to the surface wave turbulence. It quickly falls down with depth, and becomes very small in the stratified layer below $4 \mathrm{~m}$. That means that internal waves in that layer are weakly nonlinear. But at the level $20 \mathrm{~m}$ (i.e. in the near-bottom layer 2 - $3 \mathrm{~m}$ thick) correlations $<\mathrm{uv}>$ between horizontal current components sharply increase, and we should interpret the process as rather intense horizontal turbulence caused by breaking internal waves in near-bottom stratified layers.

Vertical momentum flux, represented by averaged product of horizontal velocity scalar IVI and vertical velocity $\boldsymbol{w}$ (Figure 11(b)), is of the same order as the caused by surface wave turbulence flux in the upper layer. Comparing horizontal and vertical fluxes at levels $2 \mathrm{~m}$ and $20 \mathrm{~m}$ we can conclude that relative role of vertical flux in the near-bottom layer is higher than in the wind wave mixed upper layer. That means, that fluxes caused by internal waves in near-bottom stratified layers are more three-dimensional, than surface wave fluxes in mixed surface layers.
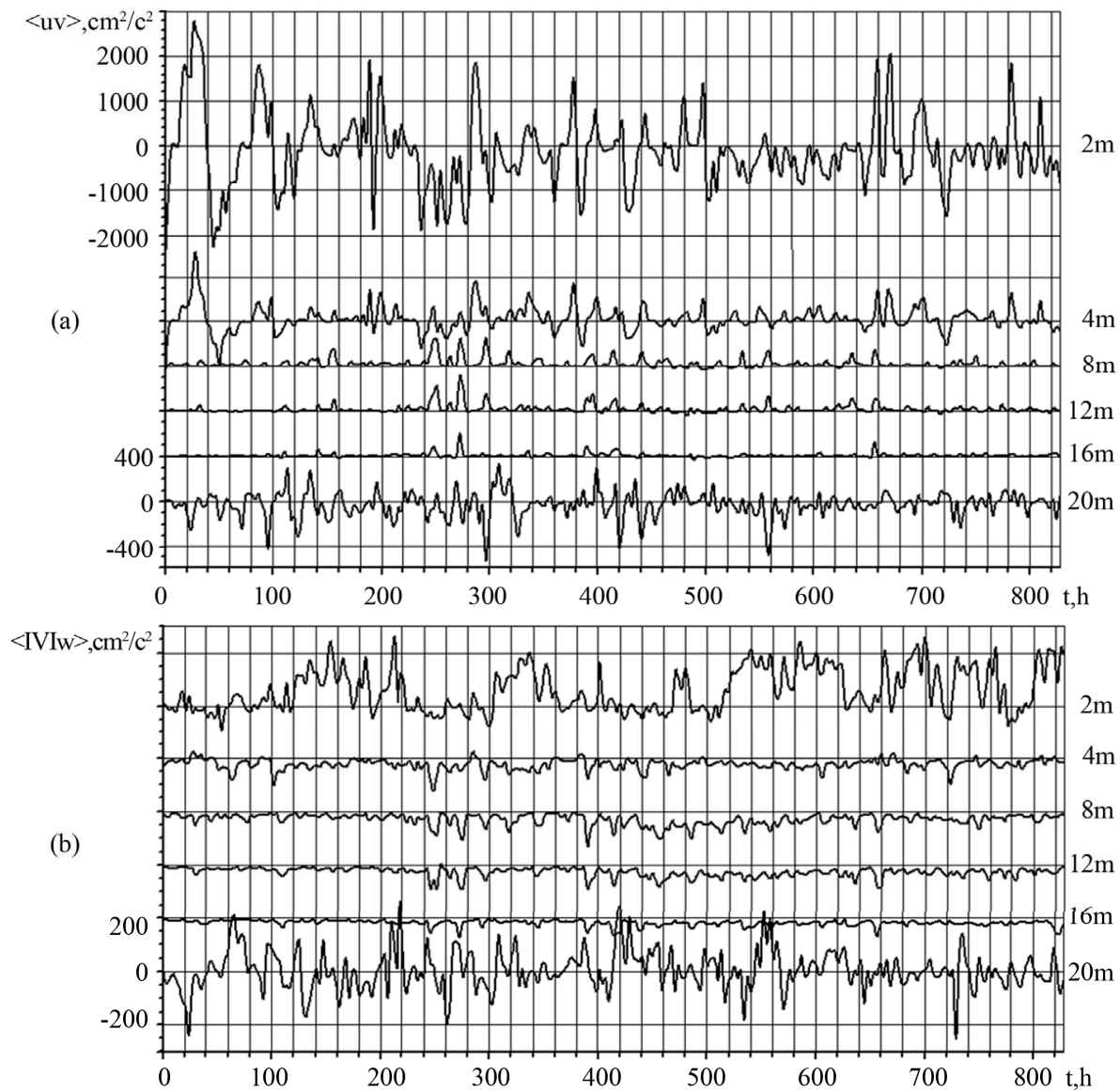

Figure 11. 3-hours averaged horizontal (a) and vertical (b) momentum fluxes at different levels during 34 days (15.08.200918.09.2009). The scale on y-axis is given for the $20 \mathrm{~m}$ level, the others are sequentially shifted up by $200 \mathrm{~cm}^{2} / \mathrm{c}^{2} . \mathrm{Bottom} \mathrm{depth}$ is $22 \mathrm{~m}$. 
Joint action of small-scale three-dimensional and larger-scale horizontal turbulence leads to quick formation of mixed waters, saturated by nutrients and minerals of terrestrial as well as sea origin. Leading role in spreading these waters over the shelf zone belongs to tides, so tidal fronts and related to them biological processes are of special interest [14]. Tidal fronts are not lines, but more or less wide zones with intense horizontal and vertical motions. Our observational results are meant to see in more detail the processes in such zones and thus help in their modeling.

\section{Conclusions}

Though a more full and more detailed processing of our experimental data is forthcoming, we can derive several interesting results from the presented here preliminary analysis of processes in the near-bottom thermocline: 1) Packets of intense high-frequency internal waves can appear and disappear in shallow waters depending on the phase of barotropic tide and on the wind driven onset and set-down of near-shore waters. In most of our previous observations of IW in the upper thermocline with lower boundary about 40 - $60 \mathrm{~m}$ from bottom [2], the IW distribution in time over the investigated area was much more homogeneous, depending mainly on large-scale changes in wind velocity. Hence we can suppose that analyzed here IW in the near-bottom thermocline are due mainly to nonlinear flow of energy from low-frequency long IW and to stratified tidal current interaction with bottom. 2) IW breaking in the near-bottom layers leads not only to vertical, but also to horizontal turbulence in the range of IW periods. The resulting mixed waters, having intermediate density between upper and bottom layers in the open sea, are flowing back from shores in the ebb phase at intermediate depths. In this way the mean vertical density gradient is reduced with time, facilitating vertical mixing, which is very important for the all physical and biological processes in the shelf zone. 3) The internal wave breaking in the near-bottom thermocline, producing peaks of pressure fluctuations and high horizontal velocities in splashes must be important factor of bottom deposits movement and bottom morphology formation.

The work was supported by the Russian Foundation for Basic Research, Grant No. 07-01-00149 and with financial support of the Far-Eastern Branch of Russian Academy of Sciences (grant No. 12-I I-CO-07-020) and Siberian Branch of Russian Academy of Sciences (grant No. 15).

\section{REFERENCES}

[1] V. V. Navrotsky, V. L. Izergin, and E. P. Pavlova, "Generation of Internal Waves near the Shelf Boundary,"
Transactions of Russian Academy of Sciences, Doklady Earth Sciences, Vol. 388, No. 1, 2003, pp. 84-88.

[2] V. V. Navrotsky, J. D. Lozovatsky, E. P. Pavlova and H. J. S. Fernando, "Observations of Internal Waves and Thermocline Splitting near a Shelf Break of the Sea of Japan (East Sea)," Continental Shelf Research, Vol. 24, No. 12, 2004, pp. 1375-1395. doi:10.1016/j.csr.2004.03.008

[3] V. V. Navrotsky, "Mixing Caused by Internal Waves and Turbulence: A Comparative Analysis," Journal of Marine Systems, Vol. 21, No. 1-4, 1999, pp. 131-145. doi:10.1016/S0924-7963(99)00010-X

[4] M. Klymak and J. N. Moum, "Internal Solitary Waves of Elevation Advancing on a Shoaling Shelf," Geophysical Research Letters, Vol. 30, No. 20, 2003, p. 2045.

[5] K. Lamb, "Shoaling Solitary Internal Waves: On a Criterion for the Formation of Waves with Trapped Cores," Journal of Fluid Mechanics, Vol. 478, No. 1, 2003, pp. 81-100. doi:10.1017/S0022112002003269

[6] A. Scotti and J. Pineda, "Observation of the Very Large and Steep Internal Waves of Elevation near the Massachusetts Coast," Geophysical Research Letters, Vol. 31, No. 22, 2004, Article ID: L22307. doi:10.1029/2004GL021052

[7] V. Umeyama and T. Shintani, "Visualization Analysis of Run-Up and Mixing of Internal Waves on an Upper Slope," Journal of Waterway, Port, Coastal, and Ocean Engineering, Vol. 130, No. 2, 2004, pp. 89-97. doi:10.1061/(ASCE)0733-950X(2004)130:2(89)

[8] R. Grimshaw, E. Pelinovsky and T. Talipova, "Modelling Internal Solitary Waves in the Coastal Ocean," Surveys in Geophysics, Vol. 28, No. 4, 2007, pp. 273-298. doi:10.1007/s10712-007-9020-0

[9] A Scotti, R. C. Beardsley, B. Butman and J. Pineda, "Shoaling of Nonlinear Internal Waves in Massachusetts Bay," Journal of Geophysical Research, Vol. 113, No. C8, 2008, Article ID: C08031. doi:10.1029/2008JC004726

[10] H. Van Haren, "Internal Wave-Turbulence Pressure above Sloping Sea Bottoms," Journal of Geophysical Research, Vol. 116, No. C12, 2011, Article ID: C12004. doi:10.1029/2011JC007085

[11] K.-H. Fu, Y.-H. Wang, L. St. Laurent, H. Simmons and D.-P. Wang, "Shoaling of Large-Amplitude Nonlinear Internal Waves at Dongsha Atoll in the Northern South China Sea," Continental Shelf Reaserch, Vol. 37, 2012, pp. 1-7. doi:10.1016/j.csr.2012.01.010

[12] A. N. Rutenko, "The Effect of Internal Waves on the Sound Propagation in the Shelf Zone of the Sea of Japan in Different Seasons," Acoustical Physics, Vol. 51, No. 4, 2005, pp. 449-456.

[13] A. S. Monin and R. V. Ozmidov, "Oceanic Turbulence," Gidrometeoizdat (in Russian), Leningrad, 1981, 320 p.

[14] Y.-J. Sun and Y.-K. Cho, "Tidal Front and Its Relation to the Biological Processes in Coastal Water," Ocean Science Journal, Vol. 45, No. 4, 2010, pp. 243-251. doi:10.1007/s12601-010-0022-3 